\title{
A Comparison on the Reproducibility of Parametric Bodies Used in the Virtual Garment System
}

\author{
Hee Eun Choi ${ }^{1)}$, Yun Ja Nam ${ }^{2)}$ and Hye Suk Kim ${ }^{1)}$ \\ 1) Dept. of Textiles, Merchandising and Fashion Design, Seoul National University; Seoul, Korea \\ ${ }^{2)}$ Dept. of Textiles, Merchandising and Fashion Design/Research Institute of Human Ecology, Seoul National University; Seoul, Korea
}

\begin{abstract}
Parametric bodies reproduce the actual shape of human body parts and should be convenient for general users to change size to judge the visual fit of clothes on-line. In this study, three parametric bodies(i.e. I, C, D ) were compared to verify the accuracy of the provided body dimensions and reproducibility to a target model. To compare reproducibility, the 20 s female standard virtual model developed for an apparel industry by Korean agency for technology and standards is used. The investigation of existing parameters showed that the numbers and kinds of parameters provided by each program were different with some errors in notation; in addition, some of virtual body dimensions went beyond the maximum allowable error. The result of changing each parametric body to the 20 s female standard body showed that D, C, I in order produced better reproducibility for body dimensions. There were different levels of protrusion and concavity in the virtual cross sections and virtual longitudinal sections despite the small differences in body dimensions and cross sectional areas; in addition, some parametric body was not bilateral symmetry. The results of this study can be used as basic information in the standardization of a virtual model used in a virtual garment program.
\end{abstract}

Key words : parametric body, virtual garment system, virtual body dimensions, virtual landmarks, reproducibility

\section{Introduction}

Recently, a technological development in 3D scanner and 3D apparel CAD system has made rapid progress. Moreover, 3D body data accumulated through anthropometric projects made on-line virtual fitting possible. Research and development in virtual garment system connected with CAD system are being worked actively. For example, there are Optitex 'Runway', Browzwear 'Vstitcher', Lectra 'Modaris 3D Fit', Technoa ‘i-Designer', 'i-Omni iVirds', CLO Virtual Fashion 'Marvelous', Physan 'DC Suite'(Cha \& Kang, 2013; Park \& Kim, 2008).

Virtual garment system should be made in consideration of consumer convenience and clothing manufacturing efficiency because it is a tool for evaluating fit and design of clothes on-line and contributes to the large decrease in the return rate of clothes bought through the online market. Therefore, for wide use in virtual reality, virtual models which are similar to customer's body shape should be built and reflect diverse body shape characteristics with minimum shape and size information.

Previous work about parametric body can be categorized into fit evaluation(Ko et al., 2009; Lee \& Sohn, 2012; Lim \& Istook, 2011; Nam \& Lee, 2008) and generation algorithm(Choi, 2013; Park et

†Corresponding author; Yun Ja Nam

Tel. +82-2-880-6844, Fax. +82-2-875-8359

E-mail: yunja@snu.ac.kr al., 2009; Shin et al., 2011). Recent work about parametric generation that suits body shape complied with virtual landmarks provided by each program are ambiguous. And in most fit evaluation, researchers selected a specific program and used scanned body directly; thus general purpose of parametric body's information is inadequate. Consequently, understanding the characteristic of each program is needed because different algorithm makes different fit evaluation result for the same body shape.

And virtual human body in the $3 \mathrm{D}$ measurement cannot be touched by hands so that it is hard to find virtual landmarks composed by mesh comparing with direct measurements. Therefore, universal criteria should be defined and at this point of time to standardization of virtual body dimensions and virtual landmarks for virtual human body, this study has important meaning for domestic virtual garment program's leap.

This study were conducted by two parts: (1) to investigate three parametric bodies' size changing tools to evaluate virtual body dimensions and virtual landmarks' accuracy, and (2) to compare three parametric bodies' with 20s female standard virtual model to appraise the reproducibility. This will be the basic information in the parametric development for improving fit of clothes on-line.

\section{Methods}

\subsection{Parametric body}

In this study, female parametric bodies of commercialized pro- 

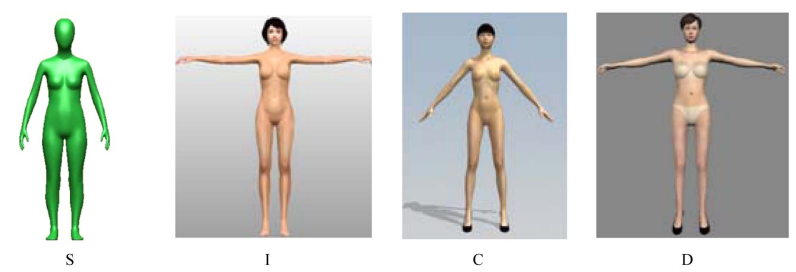

Fig. 1. 20s female standard virtual model(S) and parametric bodies (I, C, D).

gram, I, C, D were compared with a 20s female standard virtual model(Korean Agency for Technology and Standards [KATS], 2011). Fig. 1 presents parametric bodies and 20s female standard virtual model used in this study.

\subsection{Virtual body dimensions}

In this study, virtual body dimensions of a parametric body were modified for suitable virtual space with reference to 3D body automatic measurements(KATS, 2010) and for virtual body-related vocabulary, "Virtual-" prefix was used to distinguish from human body in the direct measurement(Table 1) except part 3.1(the current condition). In this study, especially, in height items, the virtual landing heel point was used instead of the ground. And virtual midthigh girth was added although it is not existed in 3D body automatic measurements(KATS, 2010), but usually used in virtual garment program for missing crotch area. Additionally, virtual armpit girth was eliminated for missing armpit area.

\subsection{Methods of analysis}

In this study, in order to verify of the accuracy of virtual body dimensions' accuracy, the right side of parametric bodies' virtual body dimensions was measured and comparing the virtual body dimensions of several parametric body regions was performed. As criteria for difference verification, maximum allowable error in 3D
anthropometry(Table 2) was used.

And for a visual comparison of the shapes of the parametric body, virtual cross sections in virtual chest, virtual bust, virtual underbust, virtual waist, virtual belly, virtual abdomen, virtual hip, virtual thigh, virtual mid-thigh and virtual longitudinal sections in virtual bust, virtual waist and virtual hip were extracted. In addition, differences of virtual flattening ratio and virtual cross sectional areas were analyzed.

Virtual landmarks of virtual cross sections and virtual longitudinal sections were differently applied(Fig. 2). For extracting each virtual cross section, virtual front neck-base point as vertical criteria and rearranged by a half of depth of maximum each virtual cross section as horizontal criteria(Kim et al., 2001). Meanwhile, virtual thigh and virtual mid-thigh, a half of width is used as vertical criteria when a virtual body is standing upright. And for the each virtual longitudinal section was divided and arranged by virtual side waist point as vertical criteria and virtual bust point, virtual front waist point, virtual hip point as each horizontal criterion.

And all the virtual body dimensions were measured by using

Table 2. Maximum allowable error in the $3 \mathrm{D}$ anthropometry (ISO, 2003)

(Unit: $\mathrm{mm}$ )

\begin{tabular}{lc}
\hline Measurement Type & Maximum difference \\
\hline Segment length(e. g., buttock-popliteal length) & 5 \\
Body heights(e. g., shoulder height) & 4 \\
Large girths(e. g., chest girth) & 9 \\
Small girths(e. g., neck girth) & 4 \\
Body breadths(e. g., biacromial breadth) & 4 \\
Body depths(e. g., chest depth) & 5 \\
Head dimensions & 1 \\
Hand dimensions & 1 \\
Foot dimensions & 1 \\
\hline
\end{tabular}

Table 1. Virtual body dimensions

\begin{tabular}{ll}
\hline Item & Virtual body dimensions \\
\hline & virtual height, virtual back neck-base height, virtual side neck-base height \\
& virtual front neck-base height, virtual shoulder height, virtual bust height \\
Height & virtual waist height, virtual belly height, virtual abdomen height, virtual hip height \\
& virtual crotch height, virtual knee height, virtual calf height \\
& virtual lower leg height, virtual ankle height \\
\hline \multirow{3}{*}{ Girth } & virtual neck girth, virtual neck-base girth, virtual chest girth, virtual bust girth \\
& virtual underbust girth, virtual waist girth, virtual belly girth, virtual hip girth \\
& virtual thigh girth, virtual mid-thigh girth, virtual knee girth, virtual calf girth \\
& virtual lower leg girth, virtual ankle girth, virtual upper arm girth, virtual elbow girth \\
& virtual lower arm girth, virtual wrist girth \\
\hline \multirow{2}{*}{ Length } & virtual shoulder length, virtual back waist length, virtual upper arm length \\
& virtual arm length
\end{tabular}



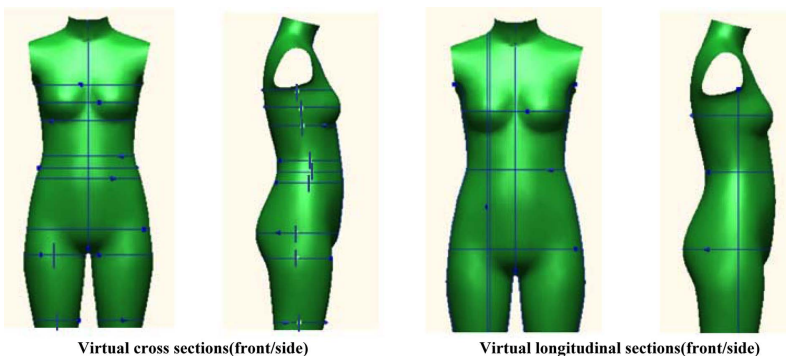

Fig. 2. Horizontal and vertical criteria of virtual cross sections and virtual longitudinal sections(S).

RapidForm 2006(INUS Technology, Inc.) and analyzed virtual flattening ratio and virtual cross section area by using Auto CAD 2008 (AUTODESK, Inc.).

\section{Result and Discussion}

\subsection{The number and classification of parameters}

Parametric body $\mathrm{C}$ contains 28 items (height 5 items, girth 13 items, length 6 items, width 4 items), parametric body D contains 20 items (height 4 items, girth 11 items, length 3 items, etc. 2 items), parametric body I contains 13 items (height 1 item, girth 10 items, length 2 items) as shown below in Table 3.

Especially, C had parameters such as back length, upper chest width, upper back width which can be used as a reference for making clothes, because they mean not the length of surface of the body but the length of each joints. Meanwhile, the height is used as stature and most of girth items are marked with 'width' despite using 'girth'. Additionally, a virtual landmark of neck height is ambiguous whether back neck-base point or front back-base point. And only chest girth is existed, therefore, in case of female parametric body bust girth and chest girth should be differentiated.

In case of $\mathrm{D}$, the notation of parameters is more accurate than any other programs and users can add other parameters and can change the virtual landmarks if necessary, regardless of provided virtual body dimension. But the explanation of crotch space and armpit space not existed in other programs is insufficient.

In case of $\mathrm{I}$, there are a few parameters, for example, length items consist of stature and crotch height only, so that the reproducibility in length is anticipated to be inferior to any other programs. And in English inscription, 'leg length' is used instead of 'crotch height'. Moreover, only the name of body is used without indicating 'girth' or 'length', consequently it causes confusion, for instance, 'upper arm', 'lower arm' could be belong to length or girth items.
Table 3. Parameters of each parametric body

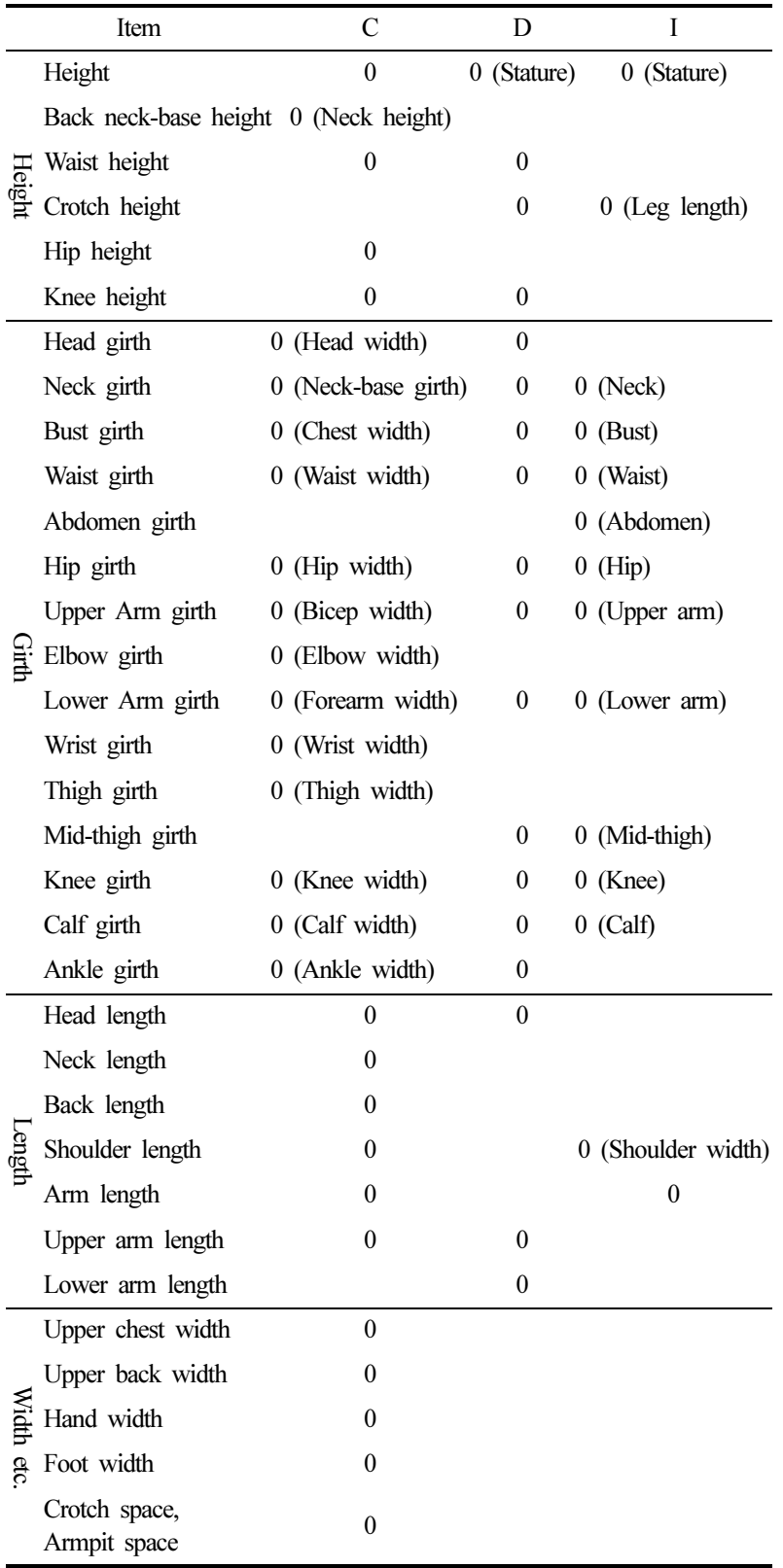

Note : In existing programs, "Virtual-" prefix is not used in parameters. Note 2: ( ) is what programs' transcription method.

\subsection{Criteria of parameters}

In this study, provided virtual body dimensions and actual virtual body dimensions are compared. Provided virtual body dimensions means virtual body dimensions provided by each program and actual virtual body dimensions means remeasured virtual body dimensions by using RapidForm 2006. There are distinct differences and the results are shown in Table 4.

In case of $\mathrm{C}$, most virtual body dimensions went beyond the 
allowable error in 3D anthropometry except virtual waist girth, virtual calf girth, virtual lower arm girth and virtual elbow girth. In height items, virtual knee height $(3.0 \mathrm{~cm})$, virtual back neck-base height $(2.8 \mathrm{~cm})$, virtual height $(2.6 \mathrm{~cm})$, virtual waist height $(2.2 \mathrm{~cm})$ in order have big differences and in girth items, virtual upper arm girth $(-7.2 \mathrm{~cm})$, virtual thigh girth $(-4 \mathrm{~cm})$, virtual chest girth $(3.4 \mathrm{~cm})$ in order have large differences. And in length items, difference from upper arm length $(1.1 \mathrm{~cm})$ causes virtual arm length difference $(1.2 \mathrm{~cm})$.

In case of $\mathrm{D}$, most virtual body dimensions went beyond the max-

Table 4. Differences of provided virtual body dimensions and actual provided body dimensions

(Unit: $\mathrm{mm}$ )

\begin{tabular}{|c|c|c|c|c|c|c|c|c|c|}
\hline $\begin{array}{l}\text { Virtual } \\
\text { body dimensions }\end{array}$ & $\begin{array}{l}\text { Provided } \\
\text { (C) }\end{array}$ & $\begin{array}{l}\text { Actual } \\
\left(\mathrm{C}^{\prime}\right)\end{array}$ & $\begin{array}{l}\text { Diff. } \\
\left(\mathrm{C}-\mathrm{C}^{\prime}\right)\end{array}$ & $\begin{array}{l}\text { Provided } \\
\text { (D) }\end{array}$ & $\begin{array}{l}\text { Actual } \\
\left(D^{\prime}\right)\end{array}$ & $\begin{array}{l}\text { Diff. } \\
\text { (D-D') }\end{array}$ & $\begin{array}{l}\text { Provided } \\
\text { (I) }\end{array}$ & $\begin{array}{l}\text { Actual } \\
\text { (I') }\end{array}$ & $\begin{array}{l}\text { Diff. } \\
\text { (I-I') }\end{array}$ \\
\hline Virtual height & 1802.0 & 1775.7 & 26.3 & 1710.0 & 1710.8 & -0.8 & 1772.8 & 1737.8 & 35.0 \\
\hline Virtual back neck-base height & 1551.0 & 1522.8 & 28.2 & - & 1473.0 & - & - & 1509.3 & - \\
\hline Virtual side neck-base height & - & 1497.3 & - & - & 1467.0 & - & - & 1502.6 & - \\
\hline Virtual front neck-base height & - & 1645.9 & - & - & 1424.0 & - & - & 1450.7 & - \\
\hline Virtual shoulder height & - & 1367.6 & - & - & 1423.0 & - & - & 1461.9 & - \\
\hline Virtual bust height & - & 1296.3 & - & - & 1253.0 & - & - & 1299.4 & - \\
\hline Virtual waist height & 1155.0 & 1133.0 & 22.0 & 1080.0 & 1098.0 & -18.0 & - & 1136.9 & - \\
\hline Virtual belly height & - & 1084.3 & - & - & 1056.0 & - & - & 1100.8 & - \\
\hline Virtual abdomen height & - & 1030.5 & - & - & 992.7 & - & - & 1036.9 & - \\
\hline Virtual hip height & 958.0 & 945.7 & 12.3 & - & 896.0 & - & - & 929.3 & - \\
\hline Virtual crotch height & - & 850.5 & - & 805.0 & 792.1 & 12.9 & 898.7 & 863.9 & 35.0 \\
\hline Virtual knee height & 510.0 & 480.0 & 30.1 & 508.0 & 499.0 & 9.0 & - & 538.2 & - \\
\hline Virtual calf height & - & 324.5 & - & - & 338.2 & - & - & 375.9 & - \\
\hline Virtual lower leg height & - & 73.5 & - & - & 101.8 & - & - & 114.3 & - \\
\hline Virtual ankle height & - & 56.3 & - & - & 73.0 & - & - & 56.4 & - \\
\hline Virtual neck girth & - & 300.4 & - & 258.0 & 255.4 & 2.6 & 302.6 & 285.5 & 17.1 \\
\hline Virtual neck-base girth & - & 379.5 & - & - & 297.4 & - & - & 356.2 & \\
\hline Virtual chest girth & 862.0 & 827.7 & 34.3 & - & 860.1 & - & 841.3 & 798.2 & 43.1 \\
\hline Virtual bust girth & - & 858.9 & - & 845.0 & 841.7 & 3.3 & - & 856.9 & - \\
\hline Virtual underbust girth & - & 750.0 & - & - & 738.4 & - & - & 767.1 & - \\
\hline Virtual waist girth & 638.0 & 635.0 & 3.0 & 689.0 & 645.3 & 43.7 & 639.5 & 638.2 & 1.3 \\
\hline Virtual belly girth & - & 689.4 & - & - & 687.4 & - & - & 669.3 & - \\
\hline Virtual abdomen girth & - & 780.2 & - & - & 831.8 & - & 839.7 & 805.9 & 33.8 \\
\hline Virtual hip girth & 900.0 & 894.5 & 5.5 & - & 906.8 & - & 934.7 & 973.8 & -39.1 \\
\hline Virtual thigh girth & 485.0 & 525.0 & -40.0 & - & 542.3 & - & - & 557.5 & - \\
\hline Virtual mid-thigh girth & - & 426.7 & - & 381.0 & 376.5 & 4.5 & 490.3 & 436.8 & 53.6 \\
\hline Virtual knee girth & 319.0 & 322.0 & -2.9 & 328.0 & 322.3 & 5.7 & 324.8 & 338.9 & -14.1 \\
\hline Virtual calf girth & 321.0 & 321.2 & -0.2 & 311.0 & 311.7 & -0.7 & 341.6 & 341.8 & -0.2 \\
\hline Virtual lower leg girth & - & 184.7 & - & - & 187.8 & - & - & 185.3 & - \\
\hline Virtual ankle girth & 187.0 & 202.7 & -15.7 & 216.0 & 224.9 & -8.9 & - & 259.5 & - \\
\hline Virtual upper arm girth & 243.0 & 315.1 & -72.1 & 212.0 & 249.3 & -37.3 & 210.5 & 272.1 & -61.6 \\
\hline Virtual elbow girth & 223.0 & 225.6 & -2.6 & - & 212.1 & - & 200.7 & 206.8 & -6.1 \\
\hline Virtual lower arm girth & 210.0 & 209.8 & 0.3 & - & 212.0 & - & - & 202.9 & - \\
\hline Virtual wrist girth & 145.0 & 148.9 & -3.9 & 139.0 & 145.1 & -6.1 & - & 134.0 & - \\
\hline Virtual shoulder length & 348.0 & 342.1 & 5.9 & 412.0 & 375.7 & 36.3 & 363.5 & 289.5 & 74.0 \\
\hline Virtual back waist length & 396.0 & 401.7 & -5.7 & - & 357.2 & - & - & 370.7 & - \\
\hline Virtual upper arm length & 309.0 & 298.4 & 10.6 & 240.0 & 294.4 & -54.4 & - & 333.5 & - \\
\hline Virtual arm length & 574.0 & 561.9 & 12.1 & 478.0 & 533.9 & -55.9 & 509.8 & 555.3 & -45.0 \\
\hline
\end{tabular}

Note : are virtual body dimensions provided by programs. 
imum allowable error in 3D anthropometry except virtual height, virtual neck girth, virtual bust girth, and virtual calf girth. In height items, virtual waist height $(-1.8 \mathrm{~cm})$, virtual crotch height $(1.3 \mathrm{~cm})$, virtual knee height $(0.9 \mathrm{~cm})$ exceeded the maximum allowable error in 3D anthropometry, but there's a few difference. Also, most of girth items are under $1 \mathrm{~cm}$ difference except virtual waist girth $(4.4 \mathrm{~cm})$, virtual upper arm girth $(-3.7 \mathrm{~cm})$. But, in length items, virtual shoulder length $(3.6 \mathrm{~cm})$ and virtual arm length $(-5.6 \mathrm{~cm})$ have significant differences, especially the difference of virtual arm length is reflected by virtual upper arm length $(-5.4 \mathrm{~cm})$.

In case of I, most virtual body dimensions went beyond the maximum allowable error in 3D anthropometry except virtual waist girth, virtual calf girth. Particularly, virtual shoulder length $(7.4 \mathrm{~cm})$, virtual upper arm girth $(-6.2 \mathrm{~cm})$, virtual mid-thigh girth $(5.4 \mathrm{~cm})$, virtual arm length $(-4.5 \mathrm{~cm})$, virtual chest girth $(4.3 \mathrm{~cm})$ have a lot of differences. Actual measurement of girth of neck is close to not virtual neck-base girth but virtual neck girth, and in that we cannot distinguish the bulge at the thyroid cartilage, a landmark when direct measurement, any part connecting neck and body is anticipated to be used. And in height items, the difference $3.5 \mathrm{~cm}$ of height items such as virtual height $(3.5 \mathrm{~cm})$ and virtual crotch height $(3.5 \mathrm{~cm})$ result from that heel height $(3.5 \mathrm{~cm})$ included the height items. Meanwhile, the cause of a difference in virtual arm length $(-4.5 \mathrm{~cm})$ is unseizable due to not having information each of virtual upper arm length and virtual lower arm length.

From this study, the girth and length items had more differences than height items, such items which have a big difference as virtual upper arm girth, virtual chest girth, virtual thigh girth, virtual midthigh girth, virtual shoulder length, virtual arm length. That is to say, different virtual landmarks were used in the same body dimensions.

In height items, the D that heel is landing on the horizontal plane was more correct than any other program, therefore using the heel of foot as the virtual landmark of height and specifying the height of heel of shoes separately prohibits users of throwing into confusions and makes better use of many kinds of shoes.

\subsection{Modeling of $20 \mathrm{~s}$ female standard virtual model using parameters}

\subsubsection{Comparisons of virtual body dimensions}

To change the parametric body similar to 20 s female standard virtual model, parameters were input to virtual body dimensions of 20s female standard virtual model(Fig. 3). After that, the comparison between virtual body dimensions of 20 s female standard virtual model and re-measurement of each parametric body are shown in Table 5. For reference, negative number means to parametric body is bigger than 20 s female standard virtual model.

In case of C, 29 items of virtual body dimensions went beyond the maximum allowable error in 3D anthropometry except virtual shoulder height, virtual ankle height, virtual neck-base girth, virtual waist girth, virtual knee girth, virtual lower leg girth, virtual ankle girth virtual elbow girth and virtual lower arm girth. Especially, in height items, virtual crotch height $(4.8 \mathrm{~cm})$, virtual abdomen height $(4.3 \mathrm{~cm})$, virtual height $(2.8 \mathrm{~cm})$, virtual lower leg height $(2.2 \mathrm{~cm})$, virtual hip height $(2.0 \mathrm{~cm})$ in order have a lot of differences and in girth items, virtual hip girth $(-7.7 \mathrm{~cm})$, virtual upper arm girth $(-6.6 \mathrm{~cm})$, virtual thigh girth $(-4.2 \mathrm{~cm})$, virtual mid-thigh girth $(-4.2 \mathrm{~cm})$, virtual underbust girth $(-4.0 \mathrm{~cm})$ in order have large differences. And in length items, virtual arm length $(4.4 \mathrm{~cm})$ and virtual shoulder length $(3.5 \mathrm{~cm})$ have a lot of differences.

In case of $\mathrm{D}, 26$ items of virtual body dimensions went beyond the maximum allowable error in 3D anthropometry except virtual height, virtual knee height, virtual lower leg height, virtual ankle height, virtual neck-base girth, virtual chest girth, virtual bust girth, virtual underbust girth, virtual hip girth, virtual thigh girth, virtual lower arm girth and virtual upper arm length. In height items, virtual back neck-base height $(-5.9 \mathrm{~cm})$, virtual front neck-base height $(-4.9 \mathrm{~cm})$, virtual shoulder height $(-4.7 \mathrm{~cm})$, virtual waist height $(-4.3 \mathrm{~cm})$ in order have big differences and in girth items, virtual calf girth $(4.4 \mathrm{~cm})$, virtual belly girth $(4.2 \mathrm{~cm})$, virtual abdomen girth $(-3.8 \mathrm{~cm})$, virtual neck-base girth $(2.2 \mathrm{~cm})$, virtual mid-thigh girth $(2.1 \mathrm{~cm})$ have large differences. And in length items, virtual shoulder length $(2.6 \mathrm{~cm})$ and virtual arm length $(-2.5 \mathrm{~cm})$ also have differences.

In case of I, 34 items of virtual body dimensions went beyond the maximum allowable error in 3D anthropometry except virtual height, virtual lower leg height, virtual waist girth and virtual wrist girth. In height items, virtual back neck-base height $(-4.2 \mathrm{~cm})$, virtual shoulder height $(-4.1 \mathrm{~cm})$, virtual bust height $(-3.8 \mathrm{~cm})$ in order have differences; this is because of small numbers of height items. In girth items, virtual abdomen girth $(8.9 \mathrm{~cm})$ and virtual belly girth $(7.0 \mathrm{~cm})$, in length items, virtual shoulder length $(8.3 \mathrm{~cm})$ and virtual arm length $(-6.9 \mathrm{~cm})$ have great differences.

Therefore, based on the maximum allowable error in $3 \mathrm{D}$ anthropometry, D, C, I in order have a high quality of reproducibility for virtual body dimensions, and virtual body dimensions which make great differences need to be increased the number of the parameters or re-established transform algorithm between virtual body dimensions.

And each parametric body has its own distinct characteristics in changing to the 20 s female standard virtual model. D, I had bigger differences in height and length items than girth items, this is because of changing parameter is mainly with girth items. But girth items which do not belong to changing parameter had also big difference, for example, virtual belly girth and virtual abdomen girth 

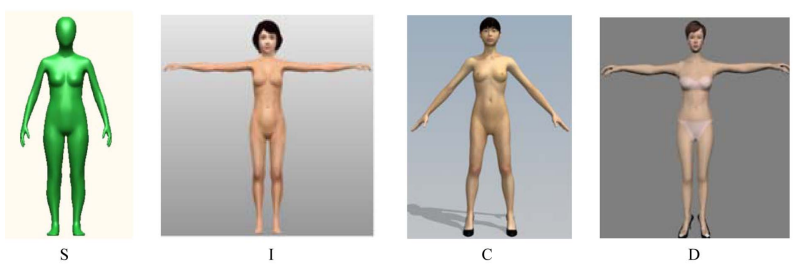

Fig. 3. Size changed parametric bodies. of I and D. For overweight people, virtual abdomen girth is more important to evaluating the fit of pants and skirts and therefore, precise changing algorithms for virtual abdomen girth should be needed when virtual waist girth is changed or virtual abdomen girth item deserve consideration as changing parameter if necessary. On the other hand, in case of $\mathrm{C}$, virtual hip girth, virtual upper arm girth and virtual thigh girth had big differences even though they

Table 5. Differences with 20 s female standard virtual model and each parametric model

(Unit: $\mathrm{mm}$ )

\begin{tabular}{|c|c|c|c|c|c|c|c|c|}
\hline Item & virtual body dimensions & $\mathrm{S}$ & $\mathrm{C}$ & S-C & $\mathrm{D}$ & S-D & I & S-I \\
\hline \multirow{15}{*}{ Height } & Virtual height & 1632.8 & 1604.6 & 28.2 & 1634.9 & -2.1 & 1631.4 & 1.4 \\
\hline & Virtual back neck-base height & 1368.0 & 1353.4 & 14.6 & 1427.0 & -59 & 1409.9 & -41.9 \\
\hline & Virtual side neck-base height & 1362.0 & 1347.5 & 14.5 & 1403.9 & -41.9 & 1384.2 & -22.2 \\
\hline & Virtual front neck-base height & 1316.0 & 1297.2 & 18.8 & 1365.4 & -49.4 & 1337.1 & -21.1 \\
\hline & Virtual shoulder height & 1311.0 & 1312.0 & -1.0 & 1357.7 & -46.7 & 1352.1 & -41.1 \\
\hline & Virtual bust height & 1158.0 & 1152.3 & 5.7 & 1185.8 & -27.8 & 1195.6 & -37.6 \\
\hline & Virtual waist height & 1007.0 & 995.5 & 11.5 & 1049.7 & -42.7 & 1040.7 & -33.7 \\
\hline & Virtual belly height & 943.0 & 957.1 & -14.1 & 980.4 & -37.4 & 976.9 & -33.9 \\
\hline & Virtual abdomen height & 932.6 & 890.0 & 42.6 & 927.4 & 5.2 & 948.9 & -16.3 \\
\hline & Virtual hip height & 797.0 & 776.6 & 20.4 & 823.9 & -26.9 & 778.0 & 19.0 \\
\hline & Virtual crotch height & 739.0 & 690.8 & 48.2 & 723.8 & 15.2 & 722.2 & 6.8 \\
\hline & Virtual knee height & 426.0 & 412.8 & 13.2 & 426.0 & 0.0 & 435.2 & -9.2 \\
\hline & Virtual calf height & 296.0 & 291.5 & 4.5 & 287.5 & 8.5 & 329.9 & -33.9 \\
\hline & Virtual lower leg height & 109.0 & 87.4 & 21.6 & 107.9 & 1.1 & 108.3 & 0.7 \\
\hline & Virtual ankle height & 63.0 & 60.8 & 2.2 & 64.0 & -1.0 & 56.5 & 6.5 \\
\hline \multirow{19}{*}{ Girth } & Virtual neck girth & 319.4 & 315.0 & 4.4 & 319.0 & 0.4 & 298.5 & 20.4 \\
\hline & Virtual neck-base girth & 365.5 & 365.8 & -0.3 & 343.7 & 21.8 & 342.3 & 23.3 \\
\hline & Virtual chest girth & 831.9 & 844.5 & -12.6 & 840.9 & -9.0 & 800.7 & 31.2 \\
\hline & Virtual bust girth & 828.7 & 866.1 & -37.4 & 824.0 & 4.7 & 846.1 & -17.4 \\
\hline & Virtual underbust girth & 724.0 & 763.6 & -39.6 & 728.8 & -4.8 & 748.0 & -24.0 \\
\hline & Virtual waist girth & 674.3 & 673.1 & 1.2 & 659.6 & 14.7 & 672.3 & 2.0 \\
\hline & Virtual belly girth & 764.4 & 720.2 & 44.2 & 722.5 & 41.9 & 694.8 & 69.6 \\
\hline & Virtual abdomen girth & 798.9 & 814.7 & -15.8 & 837.1 & -38.2 & 710.2 & 88.7 \\
\hline & Virtual hip girth & 913.6 & 990.7 & -77.1 & 914.8 & -1.2 & 964.5 & -50.9 \\
\hline & Virtual thigh girth & 540.2 & 582.0 & -41.8 & 545.9 & -5.7 & 553.0 & -12.8 \\
\hline & Virtual mid-thigh girth & 441.4 & 483.4 & -42.0 & 420.5 & 20.9 & 453.5 & -12.1 \\
\hline & Virtual knee girth & 358.6 & 358.6 & 0.0 & 351.1 & 7.5 & 364.7 & -6.1 \\
\hline & Virtual calf girth & 343.4 & 350.3 & -6.9 & 299.5 & 43.9 & 349.5 & -6.1 \\
\hline & Virtual lower leg girth & 204.1 & 206.7 & -2.6 & 188.6 & 15.5 & 171.2 & 32.9 \\
\hline & Virtual ankle girth & 218.7 & 222.7 & -4.0 & 235.7 & -17.0 & 238.7 & -20.0 \\
\hline & Virtual upper arm girth & 260.5 & 326.3 & -65.8 & 256.1 & 4.4 & 217.4 & 43.1 \\
\hline & Virtual elbow girth & 216.3 & 213.0 & 3.3 & 208.5 & 7.8 & 192.5 & 23.8 \\
\hline & Virtual lower arm girth & 213.3 & 212.5 & 0.8 & 210.3 & 3.0 & 195.0 & 18.3 \\
\hline & Virtual wrist girth & 145.1 & 160.0 & -14.9 & 137.0 & 8.1 & 144.1 & 1.0 \\
\hline \multirow{4}{*}{ Length } & Virtual shoulder length & 381.6 & 347.0 & 34.6 & 355.4 & 26.2 & 298.4 & 83.2 \\
\hline & Virtual back waist length & 375.6 & 364.4 & 11.2 & 383.4 & -7.8 & 354.4 & 21.2 \\
\hline & Virtual upper arm length & 309.3 & 315.0 & -5.7 & 313.4 & -4.1 & 346.4 & -37.1 \\
\hline & Virtual arm length & 537.9 & 494.1 & 43.8 & 562.6 & -24.7 & 606.6 & -68.7 \\
\hline
\end{tabular}


belong to changing parameters. This is because of incorrect virtual landmarks, thus virtual landmarks of the same virtual body dimensions should be established and applied.

\subsubsection{Height items' index value}

In height items, it's hard to control virtual head length so that other height item's index value are compared to virtual back neckbase height based on virtual landing heel point on the horizontal plane (Table 6). Virtual abdomen height, virtual crotch height and virtual calf height have more than 0.03 differences, but most index value has small differences among programs. In particular, virtual waist height/virtual neck-base height have same index value (0.74). This means, if the virtual neck-base heights of parametric bodies and virtual landing heel point, criteria of the height items are correct, other height items could be changed with the following index value. This will provide the convenience to the consumers who don't know their own height body dimensions as compared with girth body dimensions.

\subsubsection{Virtual cross sections and virtual flattening ratio}

Virtual cross sections of each program for primary regions are shown in Fig. 4 and virtual flattening ratio and width divided by thickness are shown in Fig. 5.

Virtual cross sections of virtual bust, virtual underbust, virtual waist, virtual thigh and virtual mid-thigh are seen very round and those of virtual hip and virtual chest are seen very flat. The differences of virtual flattening ratio are found highly in virtual chest, virtual bust and virtual hip. Virtual bust is in low level section (1.22-1.50) than other regions and C, D, I, S in order are more round while virtual hip is in high level section (1.58-1.88) than other regions and C, I, D, S in order are more flat. Especially, in case of virtual chest, I (1.82) and S (1.63) are flat whereas D (1.36)

Table 6. Index value of height items (with virtual back neck-base height)

\begin{tabular}{lcccc}
\hline \multicolumn{1}{c}{ Item } & $\mathrm{S}$ & $\mathrm{C}$ & $\mathrm{D}$ & $\mathrm{I}$ \\
\hline Virtual shoulder height & 0.96 & 0.97 & 0.95 & 0.96 \\
Virtual bust height & 0.85 & 0.85 & 0.83 & 0.85 \\
Virtual waist height & 0.74 & 0.74 & 0.74 & 0.74 \\
Virtual belly height & 0.69 & 0.70 & 0.68 & 0.69 \\
Virtual abdomen height & 0.68 & 0.65 & 0.65 & 0.67 \\
Virtual hip height & 0.58 & 0.57 & 0.58 & 0.55 \\
Virtual crotch height & 0.54 & 0.51 & 0.51 & 0.51 \\
Virtual knee height & 0.31 & 0.30 & 0.30 & 0.31 \\
Virtual calf height & 0.22 & 0.22 & 0.20 & 0.23 \\
Virtual lower leg height & 0.08 & 0.06 & 0.08 & 0.08 \\
Virtual ankle height & 0.05 & 0.04 & 0.04 & 0.04 \\
\hline
\end{tabular}

and $\mathrm{C}(1.33)$ are round, although $\mathrm{D}(0.9 \mathrm{~cm})$ had a small difference with $\mathrm{S}$ comparing other programs, $\mathrm{C}(-1.3 \mathrm{~cm})$ and $\mathrm{I}(3.1 \mathrm{~cm})$ in differences of virtual chest girth (Table 5).

Additionally, the cross section of D is not bilateral symmetry. In case of virtual bust, right side of $\mathrm{D}$ is inward curved comparing the left side of $\mathrm{D}$, thus, $4.0 \mathrm{~mm}$ of difference is occurred in the right side and only $0.7 \mathrm{~mm}$ is occurred in left side, consequently $4.7 \mathrm{~mm}$ of difference remained. That is to say, each program has different shapes of the virtual cross sections even if the small difference in virtual body dimensions is existed, so comparison of shape is important.

3.3.4. Virtual longitudinal sections and virtual cross sectional areas

The result of overlapping the virtual longitudinal sections to compare the extent of naturalness from virtual shoulder to virtual waist section, from virtual waist to virtual crotch section and from virtual waist to virtual mid-thigh section are shown in Fig. 6 and

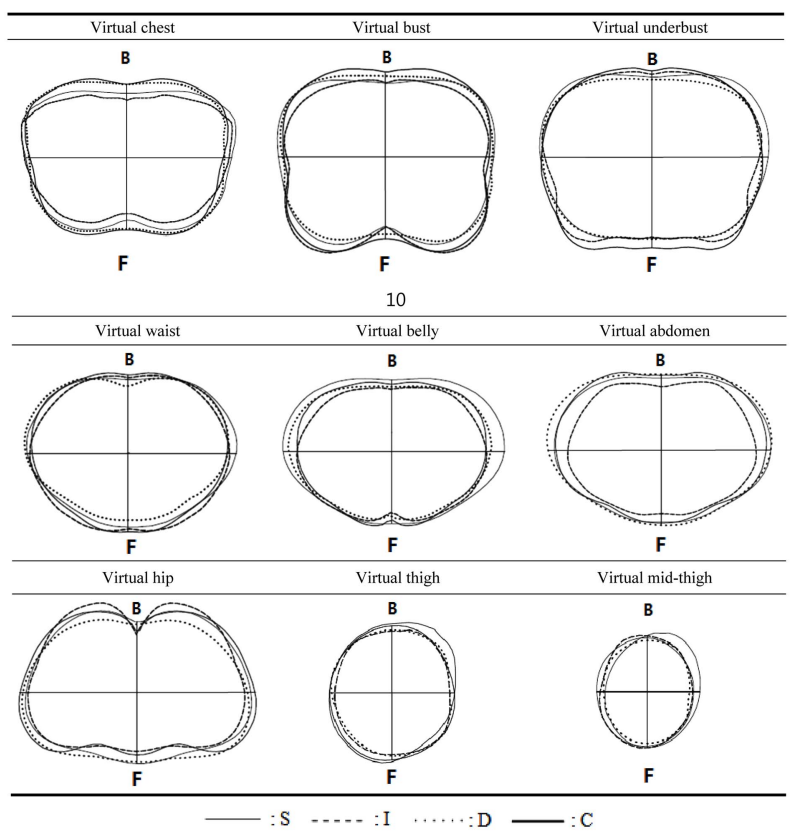

Fig. 4. Virtual cross sections of each parametric body.

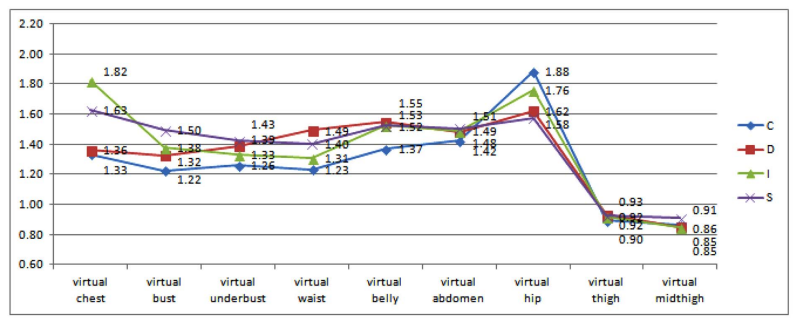

Fig. 5. Differences of virtual flattening ratio. 


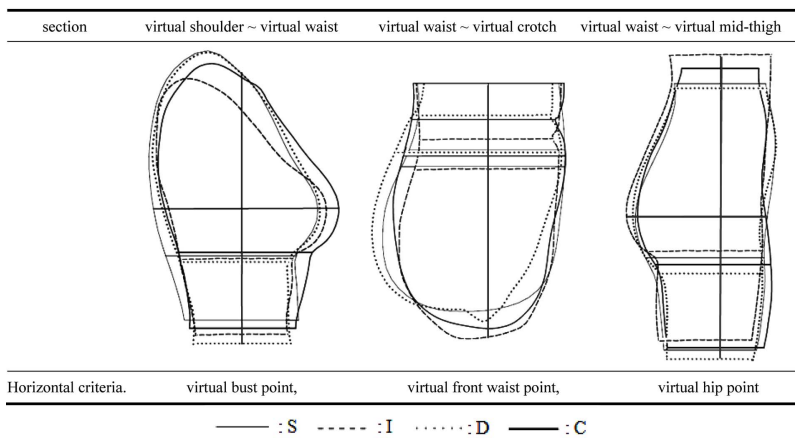

Fig. 6. Virtual longitudinal sections of each parametric body.

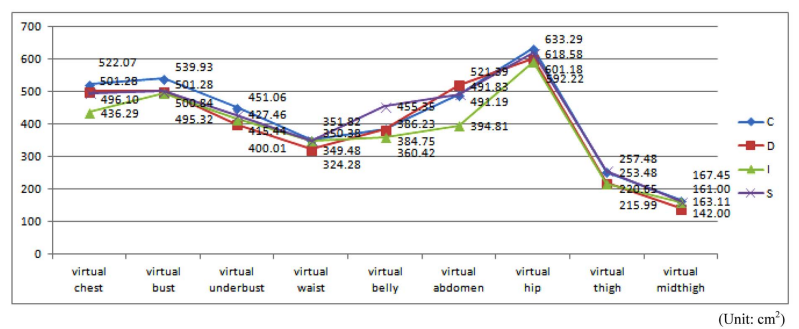

Fig. 7. Differences of virtual cross sectional areas.

differences of virtual cross sectional areas are shown in Fig. 7.

In case of the upper body, C, I, D, S in order are seen more protrusive in virtual bust region, but $\mathrm{S}$ in virtual back region is more protrusive, consequently, in the actual virtual cross sectional areas in virtual bust region $\mathrm{C}, \mathrm{D}, \mathrm{S}, \mathrm{I}$ in order are larger. But in case of I, big differences in virtual chest-virtual bust-virtual underbust areas make connecting line from virtual chest girth to virtual bust girth unnatural. Meanwhile, D with the smallest difference in virtual chest-virtual bust-virtual underbust areas is seen natural and similar to $S$ in virtual chest region. From virtual waist to virtual crotch section, there are similar virtual cross sectional areas in virtual waist girth, but virtual belly girth and virtual abdomen girth is distinguished in virtual cross sectional areas. Especially, $\mathrm{S}$ is larger than other program in virtual belly girth, while I is smaller in virtual abdomen girth as shown in the Fig. 7.

In case of the lower body, the virtual cross sectional areas is similar in virtual hip girth, virtual thigh girth and virtual mid-thigh girth, but in virtual hip height, $\mathrm{C}, \mathrm{D}, \mathrm{S}, \mathrm{I}$ in order are higher and I, $\mathrm{D}, \mathrm{S}, \mathrm{C}$ in order are more projected. And connecting line from virtual back waist point to virtual crotch point is different and the virtual crotch height of other programs is lower than $\mathrm{S}$ with different shapes. In that the shape of virtual crotch and virtual hip is important region in evaluating the pant's fit, the shape must be in consideration, not to mention the virtual body dimensions.

\section{Conclusions}

In this study, body size changing tools provided by three domestic programs were investigated to evaluate the accuracy of virtual body dimensions and three parametric bodies were compared with 20 s female standard virtual model to appraise the reproducibility. The results of this study are summarized as follows.

First, the numbers and kinds of parameters provided by each program were different, there were errors in mark using 'width' despite of 'girth' and using bust girth and chest girth mixed. Thus, terminology unification for same virtual body dimensions is needed.

Second, differences of virtual body dimensions provided by each program were found and most of items went beyond the maximum allowable error in the 3D anthropometry. Especially, the girth and length items had more differences than height items, such as virtual upper arm girth, virtual thigh girth, and virtual arm length. And some program included height of heel to the height items. Therefore, ambiguous virtual landmarks need to be re-established.

Third, the result of changing to the 20 s female standard body, D, $\mathrm{C}$, I in order had better reproducibility, in particular, $\mathrm{C}$ and I had big differences. Virtual hip girth of $\mathrm{C}$ and virtual abdomen girth of $\mathrm{I}$ had over $7 \mathrm{~cm}$ differences and in virtual crotch height of $\mathrm{C}$ and $\mathrm{I}$ had almost $5 \mathrm{~cm}$ differences, even though these virtual body dimensions are important to evaluate the fit of pants. This is also because of wrong virtual landmarks and inaccurate size changing tool. On the other hand, that is encouraging that height items' index values compared to virtual back neck-base height had minimal differences. Because reproducibility of the virtual height items for relatively small numbers of size changing tool could be improved using height items' index values.

Fourth, virtual cross sections of virtual bust, virtual underbust, virtual waist, virtual thigh and virtual mid-thigh were seen very round and virtual hip and virtual chest were seen very flat. But taking a closer look, the differences of virtual flattening ratio were found highly in virtual chest, virtual bust and virtual hip. Especially, in case of virtual chest, I (1.82) and S (1.63) were flat, whereas D (1.36) and C (1.33) were round even though D was most similar to $\mathrm{S}$ for virtual body dimensions. Additionally, $\mathrm{D}$ is even not bilateral symmetry. Therefore, not only virtual body dimensions but also shape of the virtual body regions must be in consideration in making a parametric body and evaluating the fit of clothes.

Fifth, in case of I, with great differences of virtual cross sectional areas from virtual chest girth to virtual bust girth was unnatural, in 
case of $\mathrm{D}$ with a most similar of virtual cross sectional areas was natural. On the other hand, virtual hip with similar areas in each program was found different the extent of protruding back and forth. That means, analysis of fit require shape observation, because different shapes could be existed even though a same virtual cross section has similar areas.

Parametric body is developed and used for purpose on fitting online instead of using user's scanned body. Therefore, ease of use and accurate size changing is essential. But existing domestic parametric body used in a virtual garment program is lack of unification of terminology and accurate virtual landmarks, consequently different size changing results.

Therefore, at this point of widely used parametric bodies, unification of terminology and standardization of virtual landmarks and virtual body dimensions should be established. And for evaluating fit and design of clothes on-line, not only size and but also shape influence the results. That is to say, from a step of making a parametric body, accurate virtual landmarks should be mapped and elaborate size changing algorithm must be established and applied.

This study is dedicated to basic information for users who want to evaluate the fit of clothes using these three domestic virtual garment programs and for developers of a parametric body for customer convenience and a follow up study should be progressed.

\section{Acknowledgments}

This study was supported by the Standardized Technology Development Project 'Establishment of Digital Human and Apparel Product Standards Using IT and Fashion Convergence Technology' (10041517) funded by the Ministry of Trade, Industry and Energy and the 'BK21 Plus' Project funded by the National Research Foundation of Korea in South Korea.

\section{References}

Cha, S. J., \& Kang, Y. K. (2013). Comparison of basic bodice block for adults women by 3D simulation. The Research Journal of Fashion business, 17(2), 63-81. doi: 10.12940/jfb.2013.17.2.63

Choi, Y. L. (2013). Size Specifications of Females Aged between 7 and 18 for 3D Body Model Development. The Research Journal of Fashion \& Textile, 15(2), 247-255. doi:10.5805/SFTI.2013.15.2.247

International Organization for Standardization. (2003). ISO 20685: 3D scanning methodologies for internationally compatible anthropometric databases. Geneva: Author.

Kim, H. K., Kwon, S. H., Kim, S. J., Park, E. J., Seo, C. Y., Lee, S. N., Jeon, E. K., \& Cho, J. M. (2001). Clothing ergonomics experimental methodology. Seoul: Kyomunsa.

Korean Agency for Technology and Standards. (2011). Developments of Standard Virtual Models for Korean men and women in their 20 s and 30s Report. Seoul: Government Printing Office.

Korean Agency for Technology and Standards. (2010). The 6th Size Korea 3D Scan \& Measurement Technical Report. Seoul: Government Printing Office.

Ko, Y. A., Choi, H. S., Choi, B. O., Jeon, I. Y., \& Ko, H. S. (2009). 3D garment construction using computer and validation. Journal of Human Computer Interaction, 2, 516-520.

Lee, M. J., \& Sohn, H. S. (2012). A comparative analysis of the different between CLO 3D avatar sizing and actual body measurement shapes. Journal of Fashion Business, 16(4), 137-151.

Lim, H. S., \& Istook, Cynthia. L. (2011). Comparative assessment of virtual garments using direct and manual avatars. The Research Journal of the Costume Culture, 19(6), 1359-1371.

Nam, Y. J., \& Lee, J. H. (2008). 3D body scan data and virtual garment simulation. Fashion Information and Technology, 5, 41-53.

Park, C. K., \& Kim, S. M. (2008). Digital convergence in IT and Fasihon : I-Fashion. Fashion Information and Technology, 5, 54-63.

Park, S. M., Nam, Y. J., \& Choi, K. M. (2009). A study of 3D virtual fitting model of men's lower bodies in forties by morphing technique. Journal of the Korean Society of Clothing and Textiles, 31(3), 463-474.

Shin, J. Y., Choi, Y. L., \& Nam, Y. J. (2011). Development of a representative model for different body shapes of 18-24 aged women-An application of a 3D morphing technique. Journal of the Korean Society of Clothing and Textiles, 13(4), 590-599.

(Received 18 October 2013; 1st Revised 17 November 2013; 2nd Revised 10 March 2013; 3rd Revised 13 March 2014; Accepted 21 March 2014)

Copyright (C) 2014 (by) the authors. This article is an open access article distributed under the terms and conditions of the Creative Commons Attribution license (http://creativecommons.org/licenses/by/3.0/), which permits unrestricted use, distribution, and reproduction in any medium, provided the original work is properly cited. 